\title{
Deformation Mechanisms Operating in TWIP/TRIP Steels Processed by Warm to Hot Working
}

\author{
V. Torganchuk, A. Belyakov* And R. Kaibyshev \\ Belgorod State University, Pobeda 85, Belgorod, 308015, Russia
}

\begin{abstract}
The mechanical properties of medium to high-Mn austenitic TWIP/TRIP steels subjected to warm to hot working were studied. The steel samples were processed by plate rolling at various temperatures ranging from $500{ }^{\circ} \mathrm{C}$ to $1150^{\circ} \mathrm{C}$. The deformation microstructures depend significantly on the rolling temperature. The discontinuous dynamic recrystallization readily developed during hot rolling at temperatures of $T \geq 800^{\circ} \mathrm{C}$, whereas the work hardened microstructures with high dislocation densities evolved by warm rolling at temperatures below $800^{\circ} \mathrm{C}$. The warm to hot rolling strengthened the steels remarkably. The ultimate tensile strength in the range of 750 $1250 \mathrm{MPa}$ and the corresponding yield strength of 300-900 MPa could be obtained by processing at designated temperature.
\end{abstract}

DOI: $10.12693 /$ APhysPolA.134.640

PACS/topics: 81.40.Lm

\section{Introduction}

High-manganese austenitic steels with twinninginduced plasticity (TWIP) or transformation-induced plasticity (TRIP) effects have attracted a great interest of materials scientists. Such steels exhibit a beneficial combination of mechanical properties. The product of tensile strength with total elongation of TWIP/TRIP steels may exceed $50000 \mathrm{MPa} \times \%$, which is significantly larger than that of other structural steels and alloys [1]. The physical mechanisms responsible for the outstanding strength-ductility combination have been the subject of numerous studies. It is generally agreed that the excellent combination of strength and ductility results from pronounced strain hardening caused by mechanical twinning in steels with stacking fault energy (SFE) ranging from 18 to $40 \mathrm{~mJ} / \mathrm{m}^{2}$ or martensitic transformation in steels with lower SFE [2]. The grain subdivision by thin twins or martensite plates with thickness of 10-40 nm [3] decreases significantly the effective grain size and hardens the steel in accordance with the Hall-Petch relationship.

Mechanical properties of metallic materials including high-Mn TWIP/TRIP steels are greatly affected by their microstructures, which in turn depend on the processing method/condition. The important structural parameters affecting the mechanical properties of steels and alloys are the grain size and the dislocation density [4]. Regarding high-Mn steels, both a decrease in the grain size by static recrystallization and an increase in the dislocation density by cold to warm working result in significant strengthening, although plasticity degrades remarkably $[5,6]$. An appropriate strength-ductility combination in the steels can be obtained owing to desired structural parameters, which are directly controlled by

\footnotetext{
*corresponding author; e-mail: belyakov@bsu.edu.ru
}

the conditions of warm to hot working [7]. However, the effect of thermo-mechanical processing conditions on the developing microstructures and mechanical behavior of high-Mn TWIP/TRIP steels has not been studied in sufficient detail. The aim of the present paper, therefore, is to report our current results on the microstructure evolution during warm to hot rolling and mechanical properties of advanced high-Mn steels.

\section{Experimental}

The starting materials, $\mathrm{Fe}-12 \mathrm{Mn}-0.6 \mathrm{C}-1.5 \mathrm{Al}$, Fe $18 \mathrm{Mn}-0.4 \mathrm{C}$ and $\mathrm{Fe}-18 \mathrm{Mn}-0.6 \mathrm{C}$ (all in wt\%), were hot rolled at $1150^{\circ} \mathrm{C}$. Subsequently, the steel plates were processed by rolling at various temperatures from $500^{\circ} \mathrm{C}$ to $1100{ }^{\circ} \mathrm{C}$ to a total rolling reduction of $60 \%$. After each rolling pass with about $10 \%$ reduction, the samples were re-heated to the designated rolling temperature. The structural observations were carried out using a JEOL JEM 2100 transmission electron microscope (TEM) and a Quanta 600 scanning electron microscope (SEM) equipped with an electron back scattering diffraction (EBSD) pattern analyzer incorporating an orientation imaging microscopy (OIM) system. The mean grain size was measured using the linear intercept method on the OIM images counting the distance between highangle boundaries along the normal direction (ND). The tensile tests were performed using an INSTRON 5882 testing machine at ambient temperature under a strain rate of $10^{-3} \mathrm{~s}^{-1}$ with dog bone specimens cut along the rolling direction $(\mathrm{RD})$.

\section{Results and discussion}

Typical deformation microstructures evolved in the high-Mn steels during warm to hot rolling are shown in Fig. 1. Two types of the microstructures are developed. The uniform microstructures consisting of almost equiaxed grains with numerous annealing twins 


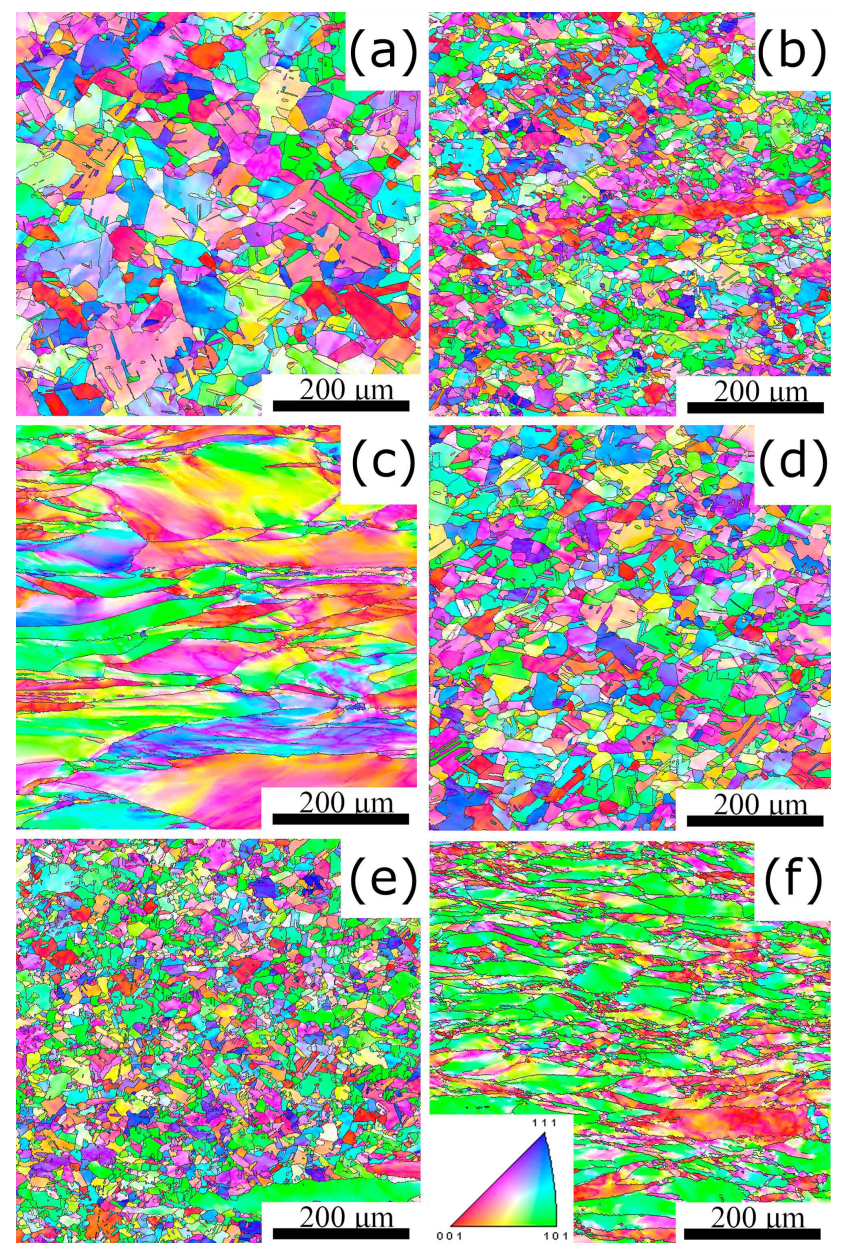

Fig. 1. Typical OIM micrographs for deformation microstructures evolved in the $\mathrm{Fe}-12 \mathrm{Mn}-0.6 \mathrm{C}-1.5 \mathrm{Al}(\mathrm{a}-$ c) and $\mathrm{Fe}-18 \mathrm{Mn}-0.6 \mathrm{C}(\mathrm{d}-\mathrm{f})$ steels during hot to warm rolling at $1000^{\circ} \mathrm{C}(\mathrm{a}, \mathrm{d}), 800^{\circ} \mathrm{C}(\mathrm{b}, \mathrm{e})$, and $600^{\circ} \mathrm{C}(\mathrm{c}, \mathrm{f})$. The colors indicate the normal direction (vertical in all pictures).

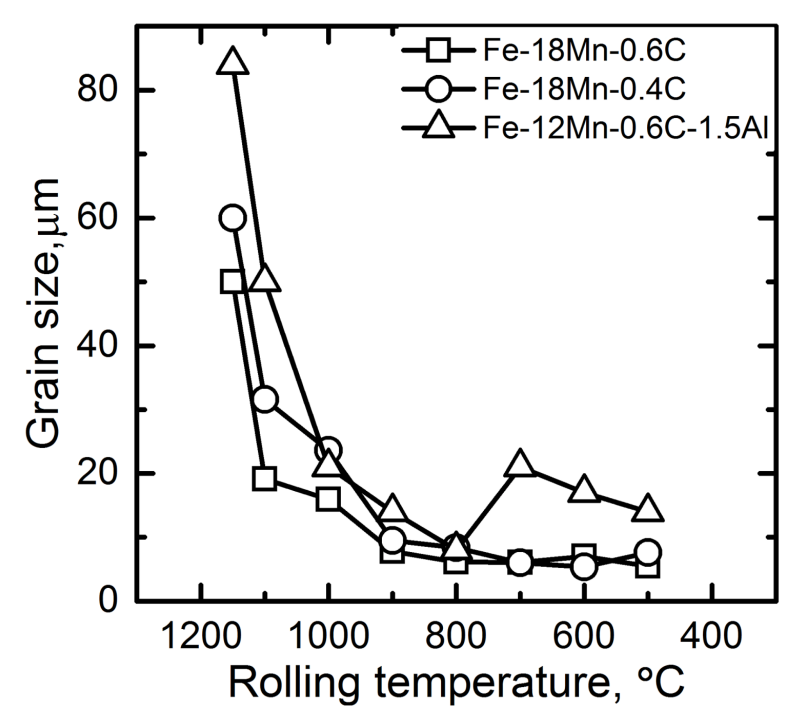

Fig. 2. Effect of the rolling temperature on the transverse grain size in the high-Mn steels.

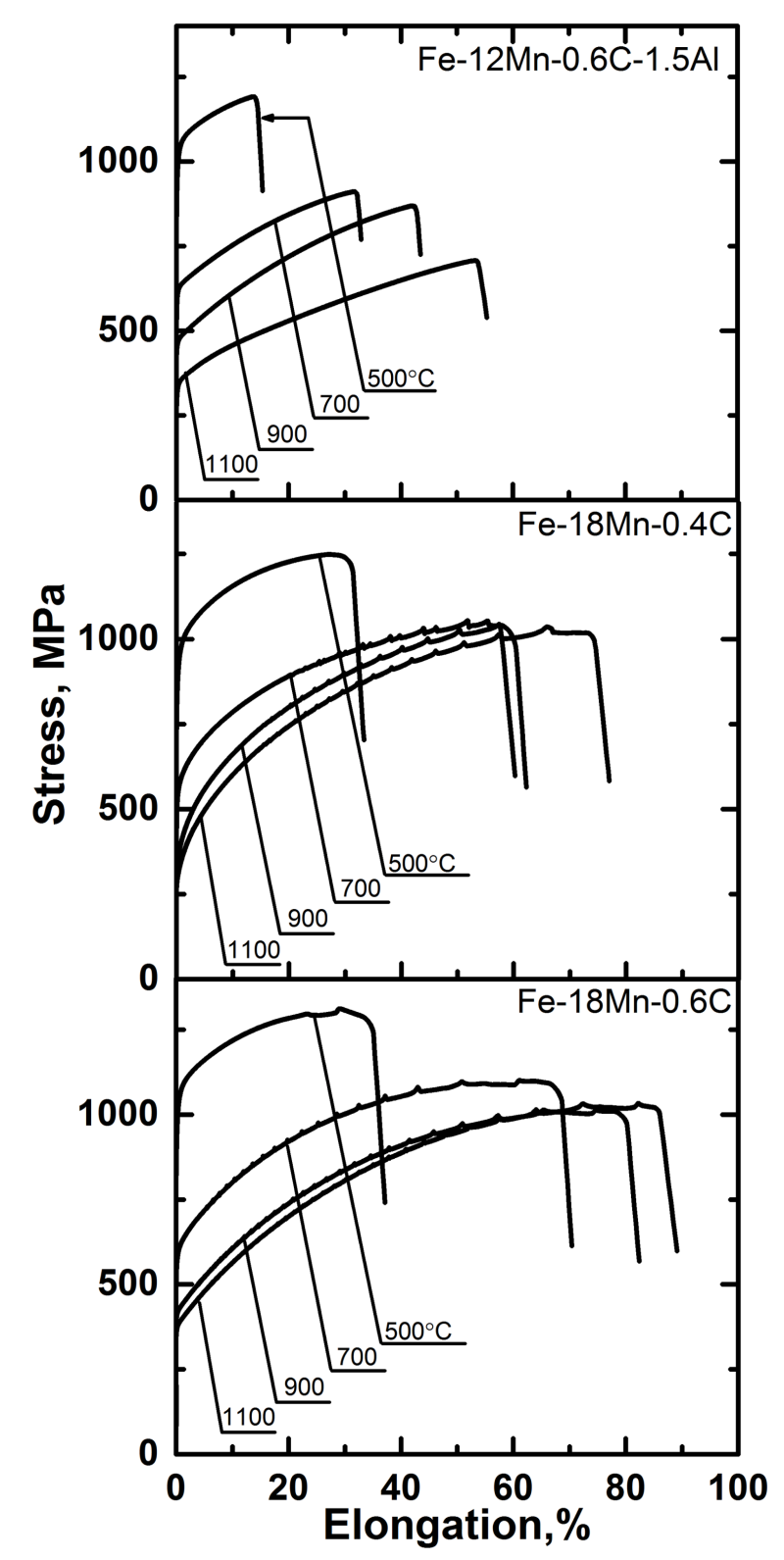

Fig. 3. Stress-elongation curves of the high-Mn steels subjected to rolling at the indicated temperatures.

evolve in the steels during hot rolling at temperatures of $T \geq 800^{\circ} \mathrm{C}$. These microstructures result from discontinuous dynamic recrystallization (DRX), which commonly takes place in low SFE steels during hot working [8]. A decrease in the deformation temperature should suppress discontinuous DRX. Indeed, the deformation microstructures composed of flattened original grains evolve during warm rolling at $T<800^{\circ} \mathrm{C}$. The transverse grain size decreases from $50-80$ to $5-10 \mu \mathrm{m}$ with a decrease in the rolling temperature from 1150 to $800{ }^{\circ} \mathrm{C}$ in the range of hot working accompanied by discontinuous DRX (Fig. 2). Further decrease in the rolling temperature below $800^{\circ} \mathrm{C}$ does not lead to remarkable variation of the transverse grain size, which seems to be dependent on the original grain size and the total rolling reduction. 


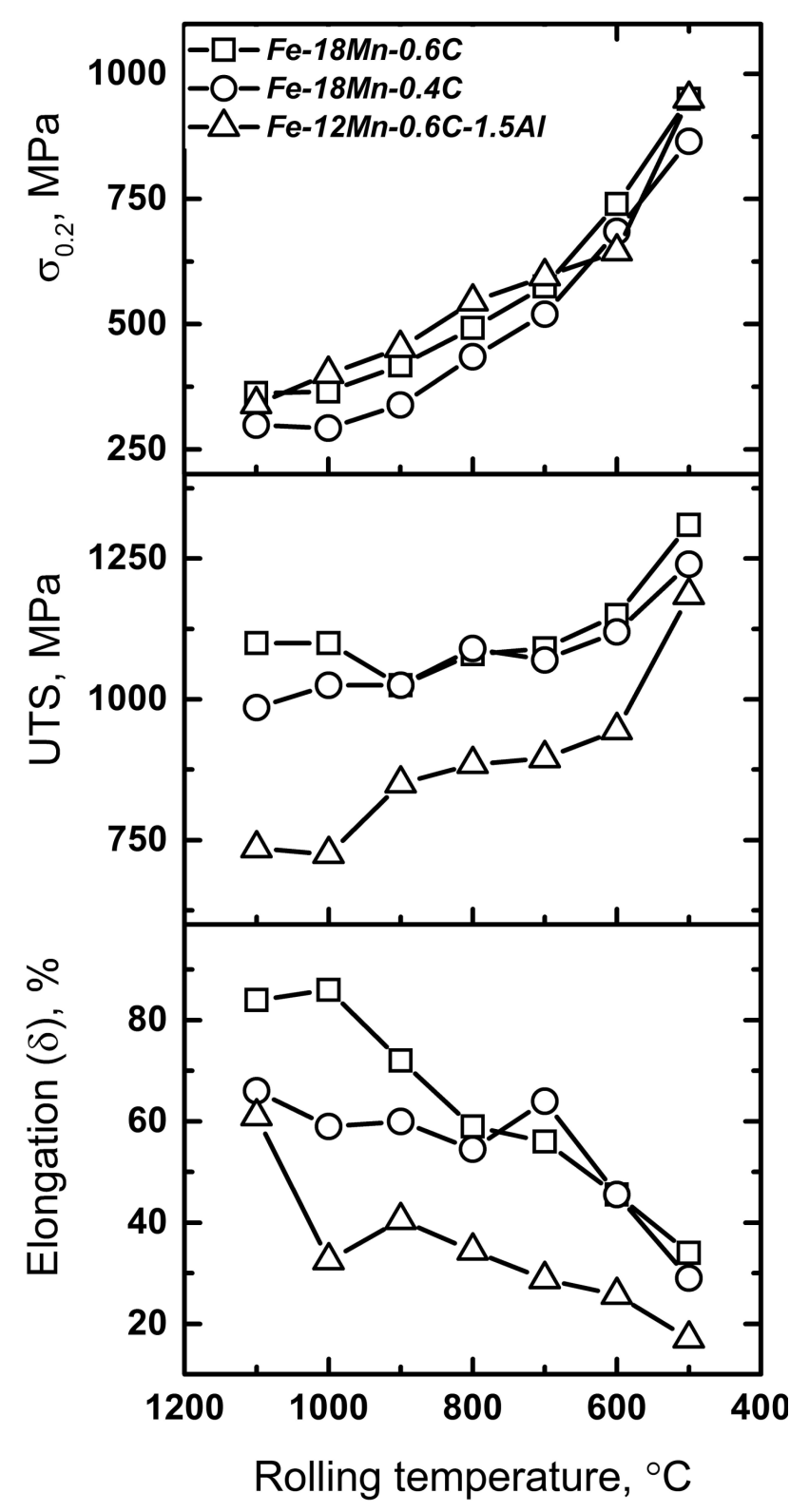

Fig. 4. Effect of the rolling temperature on the yield strength $\left(\sigma_{0.2}\right)$, the UTS, and total elongation $(\delta)$ of the high-Mn steels.

Series of tensile stress-elongation curves for the warm to hot rolled steels are shown in Fig. 3 and the mechanical properties, i.e., yield strength $\left(\sigma_{0.2}\right)$, ultimate tensile strength (UTS), and total elongation $(\delta)$, are represented in Fig. 4. Generally, a decrease in the rolling temperature results in an increase in strength and a decrease in plasticity. It should be noted that the $18 \% \mathrm{Mn}$ steels exhibit higher strength and elongation than the $12 \% \mathrm{Mn}$ steel after rolling at each temperature within the studied range. The temperature effect on the strength/ductility property of the rolled steels is more pronounced for the warm working domain than for the hot working conditions, especially, for the $18 \% \mathrm{Mn}$ steels. The yield strength pro-
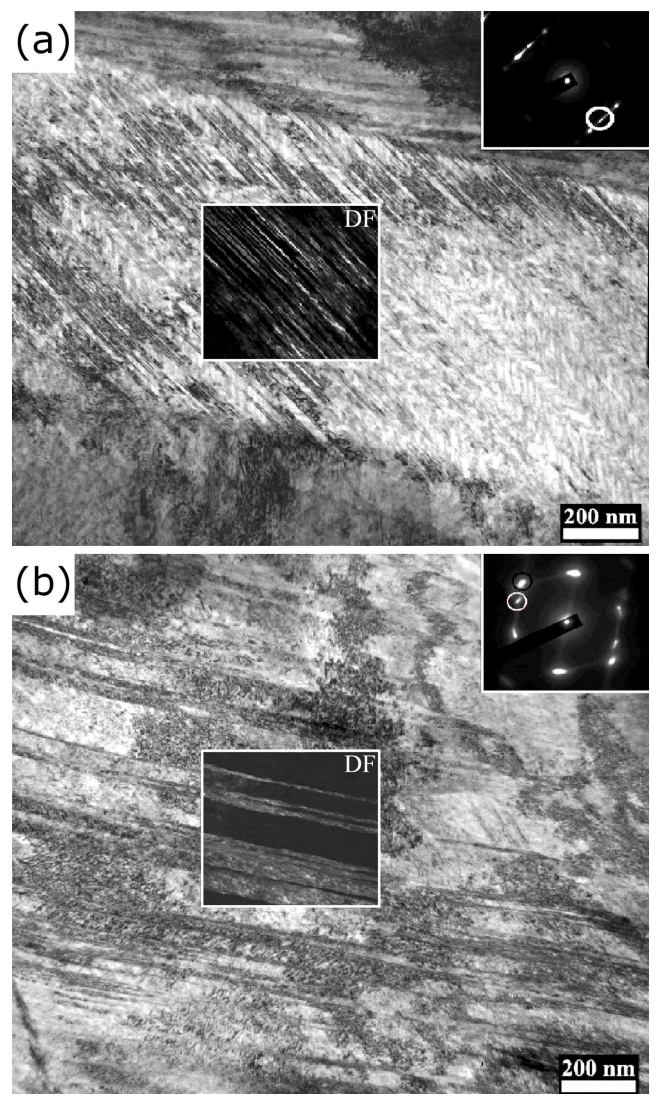

Fig. 5. TEM images of microstructures after tensile tests at room temperature of the $\mathrm{Fe}-18 \mathrm{Mn}-0.4 \mathrm{C}$ (a) and $\mathrm{Fe}-18 \mathrm{Mn}-0.6 \mathrm{C}$ (b) steels processed by rolling at $800^{\circ} \mathrm{C}$. The insets are dark field images showing deformation martensite in (a) and twining in (b).

gressively increases with a decrease in the rolling temperature, and the rate of strengthening accelerates as the temperature decreases. Similarly, UTS slightly increases with decrease of the rolling temperature from 1150 to $700{ }^{\circ} \mathrm{C}$ followed by substantial increase as the rolling temperature decreases to $500^{\circ} \mathrm{C}$, although the $12 \% \mathrm{Mn}$ steel is more susceptible to strengthening as compared to the $18 \% \mathrm{Mn}$ steels at all the rolling temperatures. The total elongations of the $\mathrm{Fe}-12 \mathrm{Mn}-0.6 \mathrm{C}-1.5 \mathrm{Al}$ and $\mathrm{Fe}-18 \mathrm{Mn}-$ $0.6 \mathrm{C}$ steels almost linearly decrease with a decrease in the rolling temperature. In contrast, the $\mathrm{Fe}-18 \mathrm{Mn}-0.4 \mathrm{C}$ steel exhibits bimodal temperature dependence for total elongation, which is about $60 \%$ after rolling at $700-1150{ }^{\circ} \mathrm{C}$ and decreases to $30 \%$ with a decrease in the rolling temperature to $500^{\circ} \mathrm{C}$.

The steels of $\mathrm{Fe}-12 \mathrm{Mn}-0.6 \mathrm{C}-1.5 \mathrm{Al}$ and $\mathrm{Fe}-18 \mathrm{Mn}-0.6 \mathrm{C}$ are characterized by monotonous dependences of the mechanical properties on the rolling temperature irrespective of the operating mechanisms of microstructure evolution in the range of $500-1150^{\circ} \mathrm{C}$. Namely, the yield strength gradually decreases while the plasticity increases with increase of the rolling temperature. However, the $\mathrm{Fe}-18 \mathrm{Mn}-0.4 \mathrm{C}$ steel demonstrates an apparent satura- 
tion for the total elongation as the rolling temperature increases above $700^{\circ} \mathrm{C}$, although the strength continuously decreases. Such a behavior can be associated with the deformation mechanisms operating during tensile tests. The $\mathrm{Fe}-18 \mathrm{Mn}-0.4 \mathrm{C}$ steel specimen experienced $\varepsilon$-martensitic transformation during tensile tests (Fig. 5a), whereas the tensile deformation of the $\mathrm{Fe}-$ $18 \mathrm{Mn}-0.6 \mathrm{C}$ steel specimen was accompanied by deformation twinning (Fig. 5b). This difference in deformation mechanisms results from the difference in SFE. The steel with lower carbon content has lower SFE [9] and, thus, involves strain-induced martensite upon cold deformation. In spite of similarities in structural parameters of deformation martensite and twinning, the latter provides much larger elongation during tensile tests. The $\mathrm{Fe}-18 \mathrm{Mn}-0.4 \mathrm{C}$ steel subjected to warm rolling at $700^{\circ} \mathrm{C}$ exhibits the maximal plasticity, which can be supported by strain-induced martensitic transformation. Hence, further increase in the rolling temperature does not improve plasticity irrespective of increase of the DRX grain size and decrease of the dislocation density, although the yield strength certainly depends on the grain size and dislocation density.

\section{Summary}

The desired combination of strength and plasticity of medium to high-Mn austenitic TWIP/TRIP steels, such as $\mathrm{Fe}-(12-18) \% \mathrm{Mn}-(0.4-0.6) \% \mathrm{C}$, can be obtained by warm to hot rolling under appropriate conditions. The ultimate tensile strength in the range of 750-1250 MPa, the yield strength of $300-900 \mathrm{MPa}$, and corresponding total elongation of $80-20 \%$ are achieved in the steels after warm to hot rolling at $500-1150{ }^{\circ} \mathrm{C}$. The yield strength of the steels gradually increases with a decrease in the rolling temperature irrespective of the mechanisms of microstructure evolution under different deformation conditions, i.e., discontinuous DRX or work hardening during hot or warm rolling, respectively. On the other hand, an increase in the total elongation by increasing the rolling temperature can be limited by deformation mechanisms. High-Mn TWIP steels with moderate SFE are characterized by increase of ductility above $80 \%$ with increase of the rolling temperature. In contrast, steels with rather low SFE exhibit TRIP effect, which do not provide total elongation above approximately $60 \%$.

\section{Acknowledgments}

The financial support received from the Ministry of Education and Science, Russia, under grant No. $11.3719 .2017 / \mathrm{PCh}$ is gratefully acknowledged.

\section{References}

[1] P.S. Kusakin, R.O. Kaibyshev, Rev. Adv. Mater. Sci. 44, 326 (2016).

[2] O. Bouaziz, S. Allain, C.P. Scott, P. Cugy, D. Barbier, Curr. Opin. Solid State Mater. Sci. 15, 141 (2011).

[3] Z. Yanushkevich, A. Belyakov, C. Haase, D.A. Molodov, R. Kaibyshev, Mater. Sci. Eng. A 651, 763 (2016).

[4] N. Hansen, Scr. Mater. 51, 801 (2004).

[5] Z. Yanushkevich, A. Belyakov, R. Kaibyshev, C. Haase, D.A. Molodov, Mater. Charact. 112, 180 (2016).

[6] P. Kusaki, K. Tsuzaki, D.A. Molodov, R. Kaibyshev, A. Belaykov, Metall. Mater. Trans. A 47A, 5704 (2016).

[7] Z. Yanushkevich, S.V. Dobatkin, A. Belyakov, R. Kaibyshev, Acta Mater. 136, 39 (2017).

[8] K. Huang, R.E. Loge, Mater. Des. 111, 548 (2016).

[9] A. Saeed-Akbari, L. Mosecker, A. Schwedt, W. Bleck, Metall. Mater. Trans. A 43A, 1688 (2012). 